\title{
Mendaur ulang sampah kantong plastik low density polyethylene menjadi produk fungsional
}

\author{
Devanny Gumulya $^{1 *}$, Febriyanti ${ }^{2}$, Fenny Meilani ${ }^{3}$ \\ ${ }^{1,2,3}$ Program Studi Desain Produk, Universitas Pelita Harapan, Tangerang, Indonesia
}

\begin{abstract}
Currently we are accustomed to disposable packaging, the habit generates a lot of waste because we are used to buying, use and dispose of when the lifespan has been exhausted with a consumption pattern like this, Indonesia has now become the world's second-largest plastic waste-producing country. With the product design approach, the student of Universitas Pelita Harapan (UPH) was tasked to recycle plastic waste in UPH environment into a functional product. Based on the results of observation and interviews, one of the waste plastic accumulated in UPH environment is the plastic shopping bag. LDPE is a thermoplastic. A type of plastic that can be formed repeatedly trough heat. The process starts by collecting, sorting, washing, then began the recycling process by heating it with oven and put them unto the mold. The purpose is to create new material that has an aesthetic quality and good structure. After the waste is processed into a functional product, the results are socialized to students from other majors in a workshop, where each participant must bring their own plastic waste materials. The result of this research and community service is a reduction in shopping bags waste that exists in UPH environment by $1 \%$, increases millennials' awareness about plastic waste in UPH, and change their perception that garbage plastic bag shopping is not rubbish that should be discarded, but a material that is ready to be recycle and made into a functional product.
\end{abstract}

Key words: LDEP plastic waste, recycling, product design.

\begin{abstract}
Abstrak
Saat ini kita sudah terbiasa dengan kemasan sekali pakai, hal ini menghasilkan sampah yang luar biasa banyak, karena kita terbiasa untuk membeli, pakai dan buang ketika masa pakainya sudah habis Dengan pola konsumsi seperti ini, Indonesia saat ini sudah menjadi negara penghasil sampah plastik kedua terbesar di dunia. Dengan pendekatan desain produk, mahasiswi Universitas Pelita Harapan (UPH) diajak untuk mengolah sampah plastik yang ada di lingkungan UPH menjadi produk fungsional. Berdasarkan hasil observasi dan wawancara, salah satu limbah plastik yang menumpuk adalah kantong plastik belanja supermarket. LDPE adalah termoplastik jenis plastik yang dapat dibentuk berulang - ulang dengan dipanaskan. Pengolahan sampah mulai dari pengumpulan, penyortiran, pencucian, baru limbah mulai didaur ulang dengan oven, dan material daur ulang dicetak dalam cetakan. Tujuannya agar material dapat kembali menjadi material yang memiliki kualitas estetis dan struktur yang baik. Setelah limbah berhasil diolah menjadi produk yang fungsional, hasilnya disosialisasikan kepada mahasiswi jurusan lain dengan mengadakan workshop, dimana setiap peserta harus membawa bahan sampah plastiknya sendiri. Hasil dari PPKM ini adalah pengurangan sampah kantong belanja yang ada di lingkungan UPH sebesar 1\% dan peningkatkan kesadaran generasi millennials akan sampah plastik yang ada di UPH dan merubah persepsi mereka bahwa sampah kantong plastik belanja bukanlah sampah yang harus dibuang, tapi material yang siap untuk diolah kembali menjadi produk pakai.
\end{abstract}

Kata kunci: plastik LDPE, daur ulang, desain produk

\section{Pendahuluan}

Limbah plastik kemasan berkontribusi sebesar 40\% dari total limbah plastik (National Geographic, 2018).
Kegiatan penelitian dan pengabdian kepada masyarakat (PPKM) ini akan mengolah sampah kemasan plastik yang ada di Lingkungan UPH dan sekitarnya. Berdasarkan observasi yang dilakukan,

\footnotetext{
* Corresponding author Tel : +62-888-8564-165 ; e-mail : devanny.gumulya@uph.edu
} 
kantong plastik belanja adalah sampah yang umum ditemukan di lingkungan kampus. Oleh karena itu, kegiatan PPKM difokuskan pada pengolahan limbah kantong plastik belanja.

Persoalan yang kemudian muncul adalah (1) bagaimana melakukan proses daur ulang limbah kantong belanja; (2) variabel apa yang mempengaruhi proses daur ulang kantong plastik belanja supermarket (jenis plastik Low Density Polyehtylene dan High Density Polyethylene); (3) bagaimana karakteristik dari material daur ulang limbah kantong plastik belanja supermarket (jenis plastik Low Density Polyehtylene dan High Density Polyethylene), dan 4) bagaimana perancangan produk dengan memperhatikan karakterisik material daur ulang kantong plastik belanja supermarket (jenis plastik Low Density Polyehtylene dan High Density Polyethylene).

Tujuan penelitian ini adalah (1) memberikan alternatif pemecahan masalah limbah plastik yang ada di lingkungan UPH dan sekitarnya; (2) mengetahui karakteristik limbah plastik setelah di daur ulang dengan teknik fusing; (3) memberi rekomendasi SOP bagaimana mendaur ulang limbah plastik dengan teknik fusing secara cepat, aman dan berkualitas secara struktur dan estetika; (4) memberi rekomendasi tutorial bagaimana membuat produk fungsional dari limbah plastik dengan teknik fusing..

\section{Bahan dan metode}

Material merupakan hal yang penting dalam riset dan praktek dalam desain produk (Ashby \& Johnson, 2009; Manzini, 1986). Dalam rangka isu global warming dan pencemaran lingkungan yang semakin meningkat, riset tentang material alternatif pengganti material yang umum dipakai juga meningkat. Penelitian tentang material dalam konteks desain, pada umumnya berfokus pada bagaimana membantu desainer memilih material dalam konteks bentuk dan teknologi produksinya (Ashby, 1999; Ashby \& Cebon, 2007; Mangonon, 1999). Dalam beberapa tahun terakhir berkembang penelitian bagaimana material membentuk pengalaman kita berinteraksi dengan sebuah produk (Ashby \& Johnson, 2009; Karana, 2009; Karana, Pedgley, \& Rognoli, 2014; Pedgley, 2009; Rognoli \& Levi, 2004; van Kesteren, 2008; Zuo, 2010 dikutip dalam Gumulya (2019). Terdapat beberapa faktor yang perlu diperhatikan dalam pemilihan material untuk menciptakan arti dari sebuah produk, yaitu sifat sensoris dan teknis material, kemiripan material, dan siapa pengguna atau target marketnya. Setiap faktor memiliki aspek-aspek lainnya yang juga perlu diperhatikan, misalnya untuk pengguna, terdapat aspek umur, jenis kelamin, keahlian, latar belakang budaya, dsb).

Setiap aspek memiliki peran yang berbeda untuk menentukan makna dari sebuah material. Material mempunyai makna tersendiri bagi penggunanya. Makna suatu material tidak selalu terlihat seperti fisik atau ciri material tersebut. Dengan adanya interaksi antara material dengan pengguna dan fungsi produk maka material yang sama bisa saja merepresentasikan makna yang berbeda dalam kondisi yang berbeda juga. Dalam arti lain, aspek tertentu yang dilihat dalam suatu benda (contoh: bentuk) dapat berubah tergantung dengan interaksi antara pengguna dan tujuan yang ingin diekspresikan melalui benda tersebut. Desainer harus memahami bagaimana sebuah material dapat memperoleh maknanya dan aspek-aspek apa saja yang mempengaruhi proses ini.

Faktor - faktor psikologi menjadi penting karena, dengan memahami psikologi manusia sebuah material baru dapat diterima lebih cepat. Sebagai contoh penemuan bioplastik PLA telah ada dari tahun 1890, namun baru mulai digunakan dan diterima masyarakat pada tahun 1960an. Menurut Manzini (1991) dikutip dalam Gumulya (2019) sebuah studi sosial budaya perlu dilakukan agar sebuah material baru dapat diterima lebih baik di masyarakat tertentu. Jadi dapat disimpulkan bahwa studi psikologi konsumen dan sosial budaya dimana material itu dipakai menjadi strategi untuk memperpendek proses adaptasi material baru. Tupperware menggunakan strategi ini untuk mengenalkan material plastik polyethylene dalam produk rumah tangga. Ketika pertama kali dikenalkan plastik diidentikkan dengan material yang murah, berkualitas rendah, dan banyak orang tidak puas dengan material plastik. Lalu plastik dibuat semirip mungkin dengan kayu, kulit yang dikenal dengan material faux. Tapi plastik masih belum memiliki identitas yang kuat di masyarakat. Clemenshaw menyebutkan bahwa Tupperwear memperkenalkan plastik polyethylene sebagai material yang fleksibel, ringan dan lembut untuk dipegang (Gumulya, 2019). Tupperwear tidak hanya menampilkan sisi fungsional dari plastik, tapi produknya juga menawarkan pengalaman baru bagi konsumen, bagaimana ketika membuka tutupnya ada suara letupan yang khas. Pengalaman sensori inilah yang membedakan Tupperware dengan kompetitor lainnya. Akhirnya bila menggunakan produk Tupperwear diasosiasikan sebagai ibu rumah tangga yang moderen dan dapur juga berkesan moderen.

Berdasarkan pengalaman sukses Tupperwear, sejak tahun 2000an para ahli mulai merasakan pentingnya dimensi psikologi, sosial dan budaya dalam 
Devanny Gumulya, Febriyanti, dan Fenny Meilani Mendaur ulang sampah kantong plastik low density polyethylene menjadi produk fungsional

membentuk pengalaman sebuah material. Maka para ahli sains material mulai melakukan penelitian berkolaborasi dengan ahli desain. Dari sinilah istilah MDD mulai terbentuk.

MDD adalah sebuah pendekatan dalam proses desain, dimana semua pengambilan keputusan desain didasarkan dari keunikan karakteristik material dengan tujuan meningkatkan pengalaman pengguna ketika berinteraksi dengan sebuah produk melalui dimensi material. Tujuan dari MDD adalah untuk mendukung para desainer bahwa material bisa dijadikan inspirasi dalam proses desain selain aspek fungsi. Dalam MDD ada empat variabel yang membentuk pengalaman seseorang akan material (Tabel 1).

Tabel 1. Empat variabel MDD

\section{SENSORIAL}

Kualitas apa yang disukai user ? (bentuk, warna, struktur, tekstur, surface, finishing)

\section{INTERPRETASI}

Material ini diasosiasikan dgn material apa? (seperti apa?)

Material ini diasosiasikan dengan makna apa ?

natural $\mathrm{x}$ sintentik, sederhana $\mathrm{x}$ elegan, nyaman $\mathrm{x}$ tidak nyaman dll

Produk jadi yang diharapkan apa?

Bila nantinya dijual di range harga berapa?

\section{AFEKTIF}

Emosi apa yang muncul ketika melihat material ini ? (tertarik $\mathrm{x}$ tidak tertarik, sedih $\mathrm{x}$ terhibur,

4. PERFOMATIF

\section{Amati tindakan apa yg} dilakukan user ketika berinteraksi dengan sampel material (mencium, menekuk, menekan2x, menerawang dll)

Penelitian dilakukan secara terstruktur dengan pendekatan kualitatif berdasarkan kerangka material driven design, yang dimulai dengan memahami properti material dengan melakukan studi literatur, eksperimen pribadi, pengenalan material secara pengalaman melalui FGD, pembentukan pola pengalaman, konsep produk, diakhir dengan kegiatan PKM untuk mendapatkan feedback riil dari masyarakat.

\section{Hasil dan pembahasan}

Terdapat dua jenis kantong plastik belanja yang tipis seperti plastik belanja supermarket (low density polyethylene/LDPE) dan plastik yang lebih tebal seperti kantong plastik Ace Hardware atau dikenal dengan high density polyethylene (HDPE). Ditelusuri lebih lanjut karakter dari masing-masing material.
Tabel 2. Karakter material HDPE dan LDPE

\begin{tabular}{|c|c|}
\hline Material HDPE & \\
\hline Sifat umum & $\begin{array}{l}\text { Sifat penghalang } \\
\text { kelembaban yang sangat } \\
\text { baik, Resistensi kimia yang } \\
\text { sangat baik } \\
\text { Sulit untuk semi - fleksibel } \\
\text { dan kuat Permukaan lilin } \\
\text { lembut } \\
\text { Permeabel terhadap gas } \\
\text { Film HDPE berkerut saat } \\
\text { disentuh Botol berpigmen } \\
\text { tahan stress }\end{array}$ \\
\hline $\begin{array}{l}\text { Tm (Melting temperature) } \\
\text { Suhu saat zat berubah dari } \\
\text { padat menjadi cair }\end{array}$ & $\begin{array}{l}130^{\circ} \mathrm{C} \text { to } 137^{0} \mathrm{C}\left(266^{0} \mathrm{C} \text { to }\right. \\
\left.280^{\circ} \mathrm{F}\right)\end{array}$ \\
\hline $\begin{array}{l}\text { Td (Decomposition } \\
\text { temperature) } \\
\text { Suhu di mana zat tersebut } \\
\text { terurai secara kimia. }\end{array}$ & $\begin{array}{l}233^{0} \mathrm{C} \text { to } 275^{0} \mathrm{C}\left(451^{0} \mathrm{~F} \text { to }\right. \\
\left.527^{0} \mathrm{~F}\right)\end{array}$ \\
\hline $\begin{array}{l}\text { Tg ( Glass transition } \\
\text { temperature) } \\
\text { Kisaran suhu di mana substrat } \\
\text { polimer berubah dari bahan } \\
\text { kaca yang kaku menjadi } \\
\text { bahan lunak (tidak meleleh), } \\
\text { dan biasanya diukur dalam hal } \\
\text { kekakuan, atau modulus. }\end{array}$ & $-110^{\circ} \mathrm{C}\left(-160^{\circ} \mathrm{F}\right)$ \\
\hline $\begin{array}{l}\text { Recommended temperature } \\
\text { range ( } I: \text { Injection, E : } \\
\text { Extrusion) }\end{array}$ & $\begin{array}{l}\text { I : } 177^{0} \mathrm{C} \text { to } 260^{\circ} \mathrm{C}\left(350^{0} \mathrm{~F} \text { to }\right. \\
\left.500^{0} \mathrm{~F}\right) \\
\mathrm{E}: 177^{0} \mathrm{C} \text { to } 274^{0} \mathrm{C}\left(350^{\circ} \mathrm{F}\right. \\
\left.\text { to } 525^{0} \mathrm{~F}\right)\end{array}$ \\
\hline Mold pressure & $12-15 \mathrm{psi}$ \\
\hline Density (gr/cm3) & $0.935-0.960$ \\
\hline \multicolumn{2}{|l|}{ Material LDPE } \\
\hline Sifat umum & $\begin{array}{l}\text { - Semi-rigid } \\
\text { - Translucent } \\
\text { - Fleksibel } \\
\text { - Kuat } \\
\text { - Tahan retak } \\
\text { - Termoplastik } \\
\text { - Tahan cuaca } \\
\text { - Tahan zat kimia } \\
\text { - Dapat didaur ulang }\end{array}$ \\
\hline $\begin{array}{l}\text { Tm (Melting temperature) } \\
\text { Suhu saat zat berubah dari } \\
\text { padat menjadi cair }\end{array}$ & $110^{\circ} \mathrm{C}(230 \mathrm{~F})$ \\
\hline $\begin{array}{l}\text { Td (Decomposition } \\
\text { temperature) } \\
\text { Suhu di mana zat tersebut } \\
\text { terurai secara kimia. }\end{array}$ & $335-450^{\circ} \mathrm{C}$ \\
\hline $\begin{array}{l}\text { Tg (Glass transition } \\
\text { temperature) } \\
\text { Kisaran suhu di mana substrat } \\
\text { polimer berubah dari bahan } \\
\text { kaca yang kaku menjadi } \\
\text { bahan lunak (tidak meleleh), } \\
\text { dan biasanya diukur dalam hal } \\
\text { kekakuan, atau modulus. }\end{array}$ & $125^{\circ} \mathrm{C}(-193 \mathrm{~F})$ \\
\hline Density $(\mathrm{gr} / \mathrm{cm} 3)$ & $0.910-0.925 \mathrm{~g} / \mathrm{cm} 3$ \\
\hline
\end{tabular}

(sumber: Strong 2006) 
Setelah dipahami properti teknis dari literatur, maka dilakukan pengenalan material secara teknis melalui eksperimen dengan material dengan 2 teknik, yaitu Teknik Molding (Tabel 3) dan Teknik Hot Press (Tabel 4)

Tabel 3. Teknik Molding

\begin{tabular}{ll}
\hline \multicolumn{2}{l}{ TEKNIK MOLDING } \\
\hline Bahan & Kantong plastik LDPE \\
\hline Alat & Oven dan Mold besi
\end{tabular}

\section{Metode pengolahan}

1. Kantong plastik dipelintir

2. Kantong plastik dimasukkan kedalam oven dengan alas besi dilapisi kalkir

3. Plastik dipanaskan pada suhu $200^{\circ} \mathrm{C}$ selama 5 menit

4. Lelehan plastik di masukkan ke dalam mold

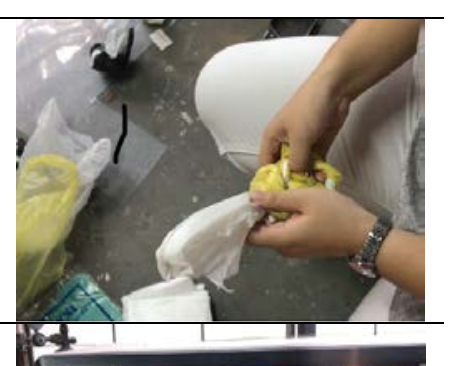

5. Mold dipress dengan ragum

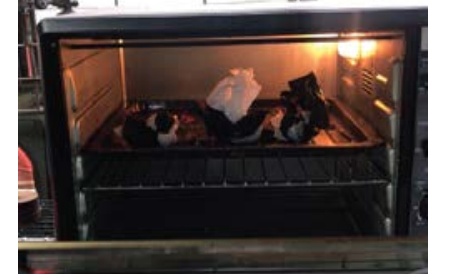

masukan ke dalan mold

(2)
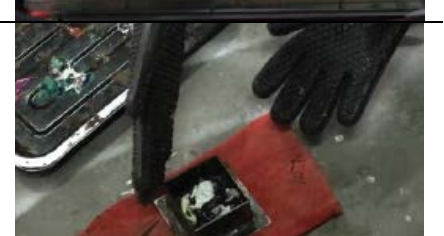

6. Sepuluh menit kemudian plastik dapat dikeluarkan dari cetakan

\section{Tabel 3. Teknik Hot Press}

\begin{tabular}{ll}
\hline \multicolumn{2}{l}{ TEKNIK HOT PRESS } \\
\hline Bahan & Serpihan tutup botol \\
\hline Alat & Hotpress
\end{tabular}

\section{Metode pengolahan}

1. Tutup botol di hancurkan hingga menjadi serpihan

2. Serpihan tutup botol di bentuk sesuai dengan yang ingin di eksplorasi yang dilapisi dengan kertas kalkir.

3. Serpihan tutup botol dipress dengan mesin hot press

4. Plastik di-press pada suhu $237^{\circ}$ C selama 15 detik

5. $\quad$ Ulangi selama $6 \mathrm{x} \quad \mathrm{di}$ bolak- balik

6. Tutup botol berhasil menjadi lembaran

Kelebihan Tidak perlu waktu lama untuk menjadikan tutup botol lembaran

Kekurangan Sulit untuk menghancurkan tutup botol secara manual dengan gunting dan kekurangan mesin penghancur tutup botol sehingga kekurangan bahan untuk di press

\begin{tabular}{ll}
\hline $\begin{array}{l}\text { Proses } \\
\text { quality }\end{array}$ & Membolak-balik kurang lebih 6x agar \\
controlatkan hasil yang maksimal
\end{tabular}

Sifat dari Playful, imperfect

materil

swatch

Selanjutnya dilakukan Focus Group Discussion (FGD) dengan topik diskusi sampel-sampel material tersebut. FGD ini dilakukan untuk mengetahui pengalaman sensori responden ketika berinteraksi dengan material ini. Peserta FGD adalah mahasiswa dan mahasiswi Universitas Pelita Harapan (UPH), Jakarta yang akan menjadi target market produk tersebut. Tujuan akhirnya adalah mengetahui respon mereka dan persepsi mereka terhadap sampel material yang dibuat. Rangkuman hasil diskusi dari berbagai pendapat responden dapat dilihat pada Gambar 1.

Eksperimen teknis dan FGD yang dilakukan menghasilkan temuan-temuan yang menarik untuk dijadikan sebagai konsep desain (Gambar 2). Material hasil olahan dari kantong plastik LDPE dipersepsikan oleh responden kuat, tebal, tidak dapat ditekuk, bertekstur kasar tetapi cukup rata, dengan pola abstrak, dan bersifat waterproof. Sedangkan material hasil olahan dari tutup botol HDPE menunjukkan sifat kuat, tipis, dapat ditekuk, bertekstur mulus tetapi tidak rata, berpola abstrak, dan waterproof. 
Devanny Gumulya, Febriyanti, dan Fenny Meilani Mendaur ulang sampah kantong plastik low density polyethylene menjadi produk fungsional

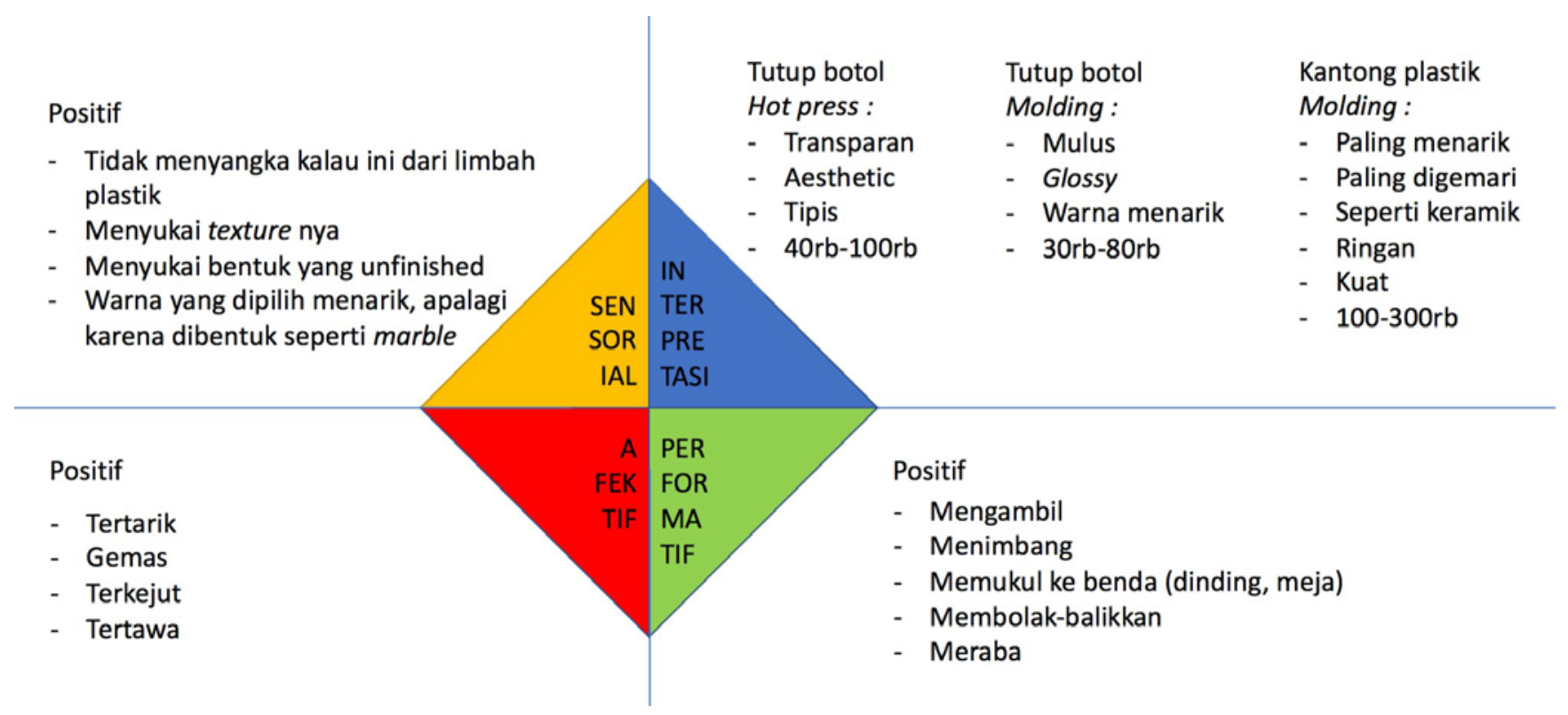

Gambar 1. Rangkuman hasil FGD

\begin{tabular}{ll}
\hline Kantong LDPE & Tutup Botol HDPE \\
\hline Kuat & \\
Tebal, tidak dapat ditekuk & Tipis, dapat ditekuk \\
Tekstur kasar, cukup rata & Tekstur mulus, tidak rata \\
Pola abstrak & Pola Abstrak \\
Waterproof & Waterproof \\
\hline
\end{tabular}

Gambar 2. Pola pengalaman material

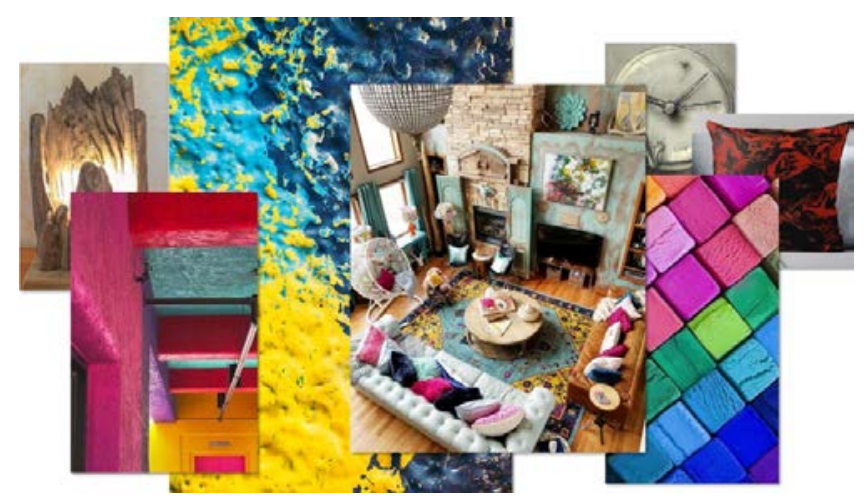

Gambar 3. Mood board
Produk yang dibuat adalah alas perhiasan dengan teknik cetak. Keunikan material yang ditampilkan di produk adalah kuat dan tekstur seperti marmer. Produk dibuat $100 \%$ dari bahan kantong plastik LDPE

Alas perhiasan yang dibuat dari 8 kantong plstik dimana 4 berwana hitam dan 4 berwarna putih. Pertama-tama lilitkan satu kantong plastik hitam dengan satu kantong plastik putih dan ikat menjadi satu gumpalan sehingga total gumpalan 4. Masukkan gumpalan kedalam oven dan dipanaskan selama 10 menit dengan suhu $230^{\circ} \mathrm{C}$. Ketika sudah panas, masukkan ke dalam cetakan berbentuk kotak dan dipress dengan alat clamping. Ketika plastik sudah dingin, keluarkan hasil cetakan dari cetakan dan pindah ke ke alat miling dan dikencangkan dengan clamping. Menggunakan mata bor milling ukuran 10 $\mathrm{mm}$ untuk melubangi plastik sehingga terdapat kedalaman.

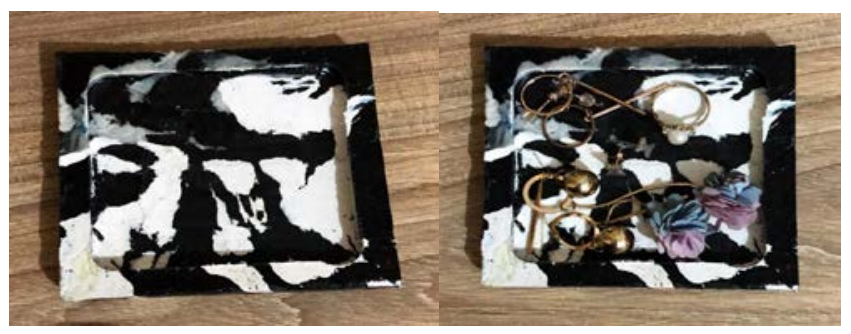

Gambar 4. Produk akhir 


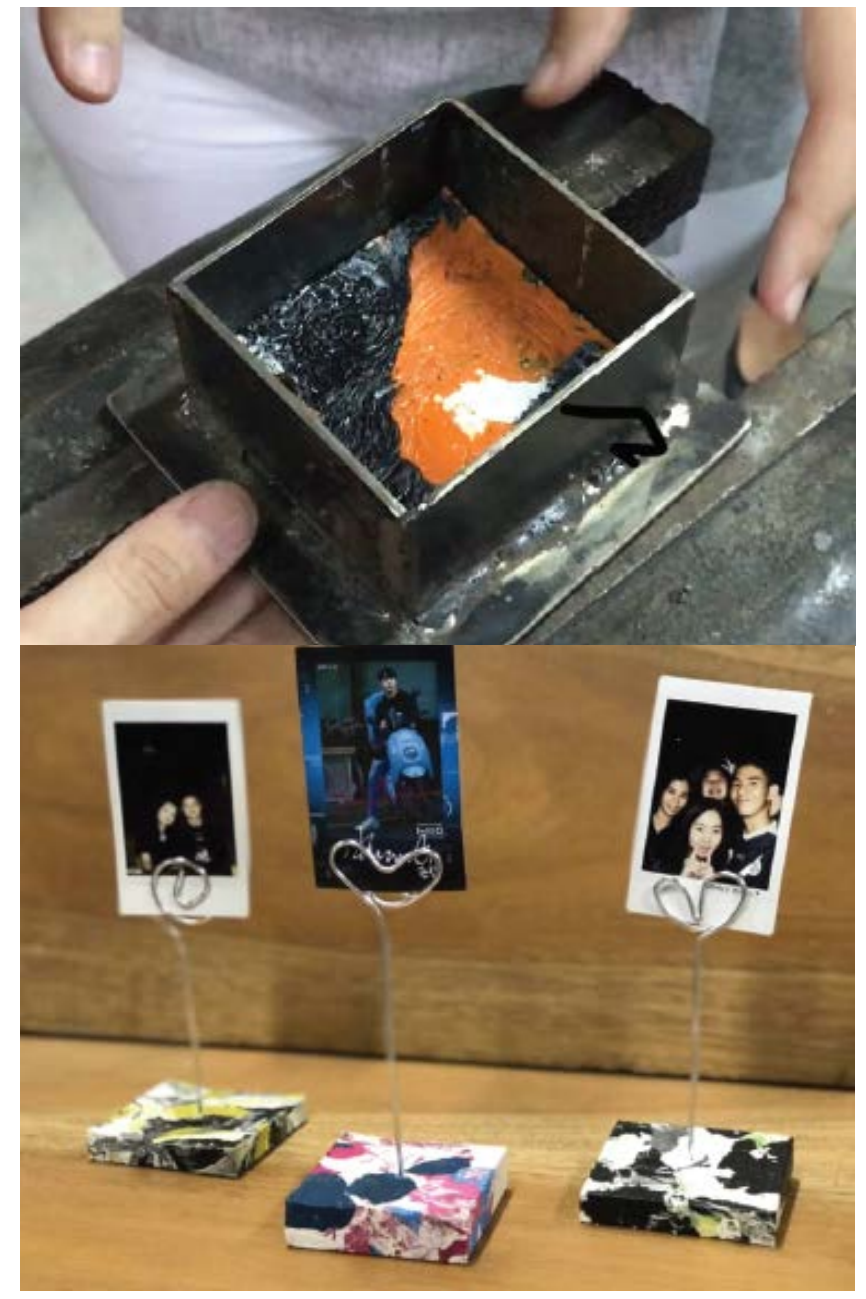

Gambar 4. Hasil kegiatan PKM

\section{Ucapan terima kasih}

Penulis ingin mengucapkan terima kasih atas bantuan, bimbingan serta kerjasama dari berbagai pihak yang telah membantu dalam penyusunan karya ilmiah ini. Penulis menyampaikan terima kasih kepada: Dr. Martin L. Katoppo S.T, M.T. (Dekan Fakultas Desain, Universitas Pelita Harapan) dan Dr. Ing. Ihan Martoyo, S.T., M.Sc (Ketua LPPM Universitas Pelita Harapan).

Artikel ini merupakan bagian dari publikasi penelitian internal UPH dengan No. P-004SOD/I/2019.

\section{Daftar pustaka}

Ashby, M., \& Cebon, D. (2007). Teaching engineering materials: The CES EduPack. Retrieved June 1, 2015, from

http://web.mit.edu/course/3/3.225/refs/Teaching_Engine ering_Materials.pdf

Ashby, M., \& Johnson, K. (2009). Materials and design. The art and science of material selection in product design ( $2^{\text {nd }}$ ed.). Oxford, UK: Butterworth-Heinemann Elsevier.

Gray, C., Burnett, G. (2009). Making sense: An exploration of ways of knowing generated through practice and reflection in craft. In: Proceedings of the Crafticulation and Education Conference, 44-51. Helsinki, Finland: NordFo.

Karana, E., (2009). Meanings of materials (Doctoral dissertation). Delft University of Technology, Delft, the Netherlands.

Karana, E., Barati, B., Rognoli, V., \& Zeeuw van der Laan, A. (2015). Material driven design (MDD): A method to design for material experiences. International Journal of Design, 9(2), 35-54.

National Geographic. (2018, May 18) Plastics 101. Retrieved December 6, 2019 from https://www.youtube.com/watch?v=ggh0Ptk3VGE

Manzini, E., \& Petrillo, A. (1991) Neolite. Metamorfosi delle plastiche [Neolite. Metamorphosis of plastics]. Milan, Italy: Domus Academy. 